\title{
The desmopressin test as a predictive factor of outcome after pituitary surgery for Cushing's disease
}

\author{
René Valéro $^{1,2}$, Sophie Vallette-Kasic ${ }^{1}$, Bernard Conte-Devolx ${ }^{1}$, Philippe Jaquet ${ }^{1}$ and $^{\text {Thierry Brue }}{ }^{1}$ \\ ${ }^{1}$ Department of Endocrinology, Hôpital de la Timone, Marseille, France and ${ }^{2}$ Department of Nutrition, Metabolic Diseases and Endocrinology, \\ Hôpital Sainte-Marguerite, Marseille, France
}

(Correspondence should be addressed to T Brue, Hôpital de la Timone, 264 rue St Pierre, 13385 Marseille cedex 5, France:

Email: Thierry.Brue@mail.ap-hm.fr)

\begin{abstract}
Objective: Taking advantage of the over-expression of $\mathrm{V} 3$ receptors in adenomatous corticotroph cells, we evaluated the response to the vasopressin agonist desmopressin in 22 patients operated on for Cushing's disease, with a mean follow-up of 4.5 years.

Subjects and methods: Twenty-two patients (17 women) operated on for Cushing's disease with a follow-up $>2$ years (median, 48; range, 24-141 months) underwent one desmopressin test (10 $\mu$ g i.v. bolus) 3-6 months postoperatively. Twelve were in remission (R group), five had immediate failure (IF) after surgery and five had late recurrence (LR).

Results: Both ACTH and cortisol peaks after desmopressin were significantly lower in the R group than in the LR group $(P=0.003$ and $P=0.013$ respectively). The receiver operator characteristic curve method defined an ACTH peak threshold $\geq 22 \mathrm{pg} / \mathrm{ml}$ or ACTH rise $\geq 35 \%$; cortisol peak $\geq 350 \mathrm{nmol} / \mathrm{l}$ or cortisol rise $\geq 14 \%$. None of twelve patients in remission had ACTH or cortisol peaks above these thresholds vs three of five patients from the LR group and five of five in the IF group.

Discussion: On the basis of ACTH or cortisol peaks respectively, the desmopressin test was predictive of a later recurrence with a positive predictive value of $100 \%$ or $80 \%$ respectively, and a negative predictive value of $92 \%$. Sensitivity and specificity were $80 \%$ and $100 \%$ respectively based on ACTH peak, and $80 \%$ and $92 \%$ respectively based on cortisol peak.

Conclusion: In this first long-term study, a marked response of ACTH or cortisol to desmopressin was predictive of a later recurrence with good specificity and sensitivity.
\end{abstract}

European Journal of Endocrinology $151727-733$

\section{Introduction}

Cushing's disease results from an adrenocorticotropin (ACTH)-secreting pituitary adenoma that induces an excess of cortisol secretion by the adrenals. Albeit rare, with an incidence estimated between two and six per million, this condition represents the first cause of endogenous hypercortisolism in adults (1). Transsphenoidal pituitary surgery has long been considered as the treatment of choice for this disease $(2,3)$ with immediate cure rates ranging from 69 to 94\% (1, 4-10). Recurrence rates, however, may be as high as $30 \%$ at 5 years $(1,4,7,8,11)$. Hypercortisolism usually recurs within 2 years, but may do so several years after surgery $(8,11)$. Information about whether patients have been cured by surgery is a challenge to endocrinologists (12). There is indeed no consensus on the parameters that may best predict such long-term recurrences.

Studies to try and identify patients at higher risk of late recurrence after pituitary surgery, who could benefit from an intensified follow-up, have addressed this point with controversial results $(1,4-6,9,11$, 13-21). Among the various agents that may interfere with the complex regulation of the hypothalamuspituitary-adrenal axis, vasopressin is one of the most powerful stimuli of ACTH secretion via its binding to pituitary V3 receptors $(22,23)$. Desmopressin is a vasopressin agonist with a longer time of action and a better clinical tolerance. Taking advantage of the overexpression of $\mathrm{V} 3$ receptors in corticotroph adenoma cells (24), the desmopressin test has been proposed as a useful investigation in the evaluation and differential diagnosis of ACTH-dependent hypercortisolism (25-31). This test was also recently found to be a valuable tool in the early postoperative evaluation of patients with Cushing's disease $(17,30,32)$.

The aim of our study was to assess the value of a postoperative desmopressin stimulation test as a predictor of long-term recurrence of surgically treated Cushing's disease. In the present report, we prospectively evaluated this test in 22 patients operated on 
for Cushing's disease in a single center, with a mean duration of follow-up of 4.5 years, and at least 2 years after surgery. In this first long-term study, we found that a marked response of plasma ACTH or cortisol to desmopressin was predictive of a later recurrence with good specificity and sensitivity.

\section{Subjects and methods}

\section{Subjects}

A population of 54 patients had been operated on for Cushing's disease in our center at least 2 years before data collection for the present study; among them 43 were available for long-term follow-up. The subset of 22 patients who had given informed consent to undergo postoperative desmopressin tests were analyzed in this study. These patients were 17 women and five men, with a mean age at diagnosis of 35 years (range, 14-57 years). The diagnosis of Cushing's disease was established on the basis of clinical features and standard hormonal criteria: high urinary free cortisol (UFC) excretion, normal or high plasma ACTH concentration, high serum cortisol concentration with loss of cortisol nychthemeral variations and lack of suppression after a low-dose dexamethasone test (1 mg orally overnight), but adequate suppression after a high-dose dexamethasone test ( $8 \mathrm{mg}$ /day orally for $48 \mathrm{~h}$ ). Inferior petrosal sinus sampling for ACTH was performed only in five patients to discriminate pituitary and ectopic sources of ACTH. Desmopressin testing was not used as a routine preoperative diagnostic procedure. Nuclear magnetic resonance imaging showed a pituitary adenoma in all other patients. The diagnosis of Cushing's disease was confirmed in 16 patients after pituitary adenomectomy, as the histological examination showed the existence of adenomatous tissue, with positive staining for ACTH at immunohistochemical analysis. In the remaining six patients, the diagnosis was confirmed by inferior petrosal sinus sampling $(n=3)$ and/or by identification of the adenoma by the neurosurgeon $(n=4)$.

After surgery, the patients were followed for at least 2 years (mean follow-up, 55 months; median, 49 months; range, 24-141 months) and were classified into two groups. The first group included twelve patients in remission ( $\mathrm{R}$ group). The patients were considered to be in remission on the basis of clinical cure, a corticotroph deficiency or normalization of urinary free cortisol excretion, and resumption of plasma ACTH and serum cortisol nychthemeral variations (midnight serum cortisol less than $50 \mathrm{nmol} / \mathrm{l}$ ) and, when available, a serum cortisol less than $50 \mathrm{nmol} / \mathrm{l}$ after a lowdose dexamethasone test.

The second group was comprised of ten patients who were not cured. This group was divided into two subgroups: five patients with immediate failure of surgery (IF group) and five patients with late recurrence (LR group) that was diagnosed $6,7,12,18$ and 36 months after surgery. The criteria for immediate failure or late recurrence were the same as those used for the diagnosis of Cushing's disease.

\section{Methods}

In each patient, plasma ACTH and cortisol values were measured every $4 \mathrm{~h}$ during $24 \mathrm{~h}(0800,1200,1600$, 2000, 2400 and $0400 \mathrm{~h}$ ), and UFC during $24 \mathrm{~h}$. These baseline ACTH and cortisol determinations were performed 6-8 days postoperatively, at 3 and 6 months, then at yearly intervals. All subjects were monitored in the neurosurgery or endocrinology departments for at least 8 days postoperatively. Some of them required early postoperative parenteral cortisol replacement therapy. In all cases, however, basal or dynamic evaluation of the pituitary adrenal axis was performed after at least 36-48 h without hydrocortisone. The most recent investigation was used for allocation into each outcome group. Plasma ACTH and cortisol, and UFC were measured by commercial radioimmunoassay kits (Beckman-Coulter-Immunotech, Marseille, France). The ACTH immunoradiometric assay had a sensitivity of $1.2 \mathrm{pg} / \mathrm{ml}$ (at $95 \%$ probability), and intra- and interassay coefficients of variation of $6.9-9.1 \%$ and $6.2-9.6 \%$ respectively. The cortisol assay had a sensitivity of $10 \mathrm{nmol} / \mathrm{l}$, and intra- and interassay coefficients of variation of $2.8-5.1 \%$ and $5.3-9.2 \%$ respectively.

All patients underwent one desmopressin test 3-6 months postoperatively. After an overnight fast, an indwelling forearm cannula was inserted at $0830 \mathrm{~h}$; the subject remained supine for the remainder of the test. At $0900 \mathrm{~h}, 10 \mu \mathrm{g}$ desmopressin (Ferring, Gentilly, France) was injected intravenously as a bolus. Plasma ACTH and cortisol concentrations were measured at $0,15,30,60,90,120$ and $180 \mathrm{~min}$ after desmopressin administration. All patients were off hydrocortisone treatment $36-48 \mathrm{~h}$ before initiation of hormone evaluation.

\section{Statistical analysis}

Statistical analysis was analyzed by Mann-Whitney's $\mathrm{U}$ test except for the differences between basal plasma ACTH and cortisol values and their secretion peaks after desmopressin injection which were analyzed using the Wilcoxon test and the sex ratio differences between groups using the $\chi^{2}$ test.

The Pearson's correlation tests were performed on appropriate variables. Statistical significance was achieved at a $P$ value less than 0.05. Determination of optimal thresholds for peak ACTH and cortisol values after desmopressin stimulation or for the percentage of variation of these values was performed using the receiver operator characteristic (ROC) curve method. 


\section{Results}

\section{Baseline and early postoperative data}

We first compared baseline parameters in the R, IF and LR groups (Table 1). Age and sex ratio were not significantly different between outcome groups. Mean duration of follow-up was longer in the LR group than in the $\mathrm{R}$ group, only reflecting the higher rate of patients unavailable to long-term follow-up in the $\mathrm{R}$ group. As expected from the definition of each group (see Methods), early mean 24-h ACTH and cortisol plasma levels as well as UFC values were statistically different between the $\mathrm{R}$ and IF groups, while patients from the $\mathrm{R}$ and LR groups had statistically comparable values, as shown in Table 1.

\section{Desmopressin test}

Individual absolute plasma ACTH and cortisol values during the desmopressin test are presented in Fig. 1. As shown in Table 2, basal plasma ACTH before desmopressin injection was, as expected, significantly lower in the $\mathrm{R}$ group than in the IF group but was not different between the $\mathrm{R}$ group and the LR group. In absolute values, the ACTH peak after the desmopressin test was significantly higher in the LR group or IF group than in the $\mathrm{R}$ group as shown on Fig. 2. Importantly, although the initial features of the $\mathrm{R}$ and the LR groups were comparable (Table 1), peak values after desmopressin were significantly higher than baseline values in the LR group but not in the $\mathrm{R}$ group (Fig. 2). The percentage rise in ACTH plasma concentration after desmopressin injection was also statistically higher in the LR group or IF group than in the $\mathrm{R}$ group (Table 2).

Basal serum cortisol before desmopressin injection was significantly lower in the $\mathrm{R}$ group than in the IF group but was not different between the $\mathrm{R}$ group and the LR group. Serum cortisol peak after the desmopressin test was significantly lower in the $\mathrm{R}$ group than in the LR group or the IF group (Table 2).

Unlike ACTH values, the percentage rise in cortisol serum concentration after desmopressin injection was not statistically different between the $\mathrm{R}$ and LR groups or between the R and IF groups (Table 2).

\section{Predictive value for surgical failure}

Using the ROC curve method, the threshold of positive stimulation after desmopressin injection was determined for each relevant parameter to try to best discriminate patients in remission (group R) from patients with later recurrence (group LR). These thresholds were the following: ACTH peak $\geq 22 \mathrm{pg} / \mathrm{ml}$ or ACTH rise $\geq 35 \%$; cortisol peak $\geq 350 \mathrm{nmol} / \mathrm{l}$ or cortisol rise $\geq 14 \%$. Performances of each individual threshold value are indicated in Table 3.

Using these criteria based on absolute values, none of the twelve patients in remission had both ACTH and cortisol values above these thresholds vs three of five patients from the LR group and five of five in the IF group. Symmetrically, ten of twelve of the patients in remission had both ACTH and cortisol values below these thresholds vs none of the patients from the LR or IF groups. Discrepant ACTH and cortisol responses were found in two of twelve patients in remission, and in two of five patients from the LR group.

\section{Discussion}

Cushing's disease is a rare disease whose spontaneously fatal evolution calls for a radical treatment. Transsphenoidal microsurgery is the treatment of choice with an immediate remission rate of $69-94 \%$ according to some studies $(1,4-10)$. Immediate surgical failures are accounted for by partial tumor removal. The recurrence rate fluctuates between 4 and $32 \%$ in the literature for an average follow-up of 5 years. Part of this variability may be due to the fact that definition of remission criteria is highly variable. Most recurrences occur within 2 years after surgery, as was the case in four of five of our patients from the LR group, but some studies report recurrences more than 10 years postoperatively $(1,13,14,20)$. Such recurrences are likely due to regrowth of residual adenomatous tissue. Several potential factors have previously been studied to try to predict long-term surgical success or failure.

Table 1 Characteristics of the population and early postoperative data in 22 patients from the R, LR and IF groups. Values are means \pm S.D.

\begin{tabular}{|c|c|c|c|c|c|}
\hline & $\mathbf{R}$ & LR & IF & $\begin{array}{c}\boldsymbol{P} \\
\mathrm{R} \text { vs } \mathrm{LR}^{\star}\end{array}$ & $\begin{array}{c}\stackrel{P}{R} \text { vs IF* } \\
\text { R }\end{array}$ \\
\hline Age (years) & $33 \pm 10$ & $32 \pm 12$ & $44 \pm 13$ & 1 & 0.073 \\
\hline Sex ratio $(F / M)$ & $9 / 3$ & $4 / 1$ & $4 / 1$ & 0.825 & 0.825 \\
\hline Follow-up (years) & $3.5 \pm 1.3$ & $7.8 \pm 3.6$ & $3.9 \pm 0.8$ & 0.033 & 0.458 \\
\hline Mean plasma ACTH (pg/ml) & $5 \pm 5$ & $10 \pm 6$ & $54 \pm 18$ & 0.138 & $<0.001$ \\
\hline Mean plasma cortisol (nmol/l) & $42 \pm 33$ & $40 \pm 44$ & $515 \pm 165$ & 0.673 & $<0.001$ \\
\hline UFC (nmol/day) & $12 \pm 26$ & $8 \pm 11$ & $571 \pm 334$ & 0.647 & 0.001 \\
\hline
\end{tabular}

* Mann-Whitney $U$ test except for sex ratio $\left(\chi^{2}\right.$ test). 


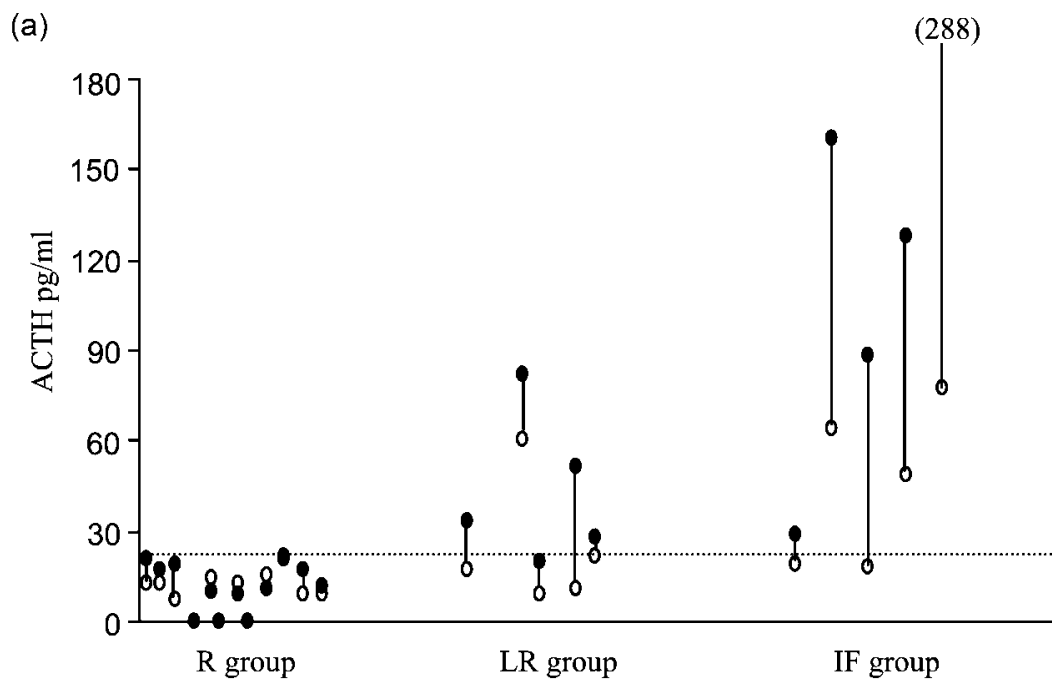

(b)

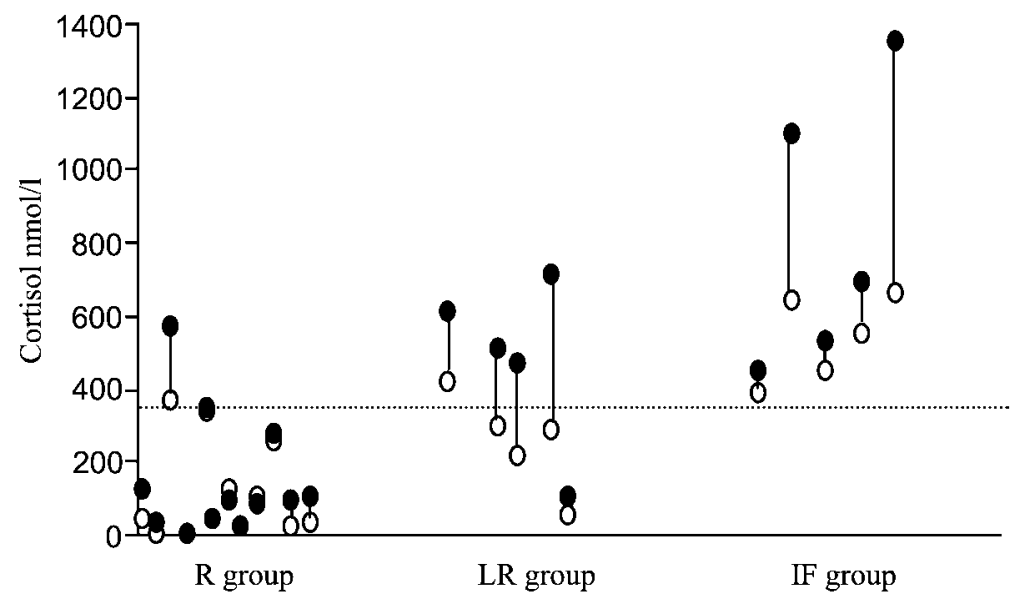

Figure 1 Individual basal and peak plasma (a) ACTH and (b) cortisol values during the desmopressin test in 22 patients after surgery for Cushing's disease. Baseline values are indicated by open circles; solid circles denote peak values after i.v. injection of $10 \mu \mathrm{g}$ desmopressin for each patient from the R, LR or IF groups. The threshold of positive stimulation as determined by ROC curve analysis is represented by the dotted lines.
Some parameters such as early postoperative cortisol levels $(1,16)$ or markers of tumor invasion (18) have been shown to provide a partial prediction of the likelihood of recurrence. For example, a serum cortisol value at $0900 \mathrm{~h}$ in excess of $100 \mathrm{nmol} / \mathrm{l}$ after pituitary surgery has been found to be associated with a higher risk of recurrence (16). Previous attempts at using dynamic tests in this setting, such as corticotropinreleasing hormone or ACTH tests, have provided controversial results $(1,19)$. In our experience, early postoperative cortisol measurements did not allow us to appropriately discriminate patients in long-term remission from those who will experience recurrence within 2-10 years (18). In our present series, early (7 days) postoperative cortisol values allowed us to identify all patients with immediate failure who had early postoperative cortisol values ranging from 291 to $731 \mathrm{nmol} / \mathrm{l}$. However, one of twelve patients in

Table 2 Mean \pm S.D. basal and peak values and percentage ACTH and cortisol during the desmopressin test in 22 patients from the R, LR and IF groups.

\begin{tabular}{lccccc}
\hline & & & & & $\boldsymbol{P}$ \\
& $\mathbf{R}$ & LR & IF & $\begin{array}{c}\boldsymbol{P} \\
\text { R vs LR* }\end{array}$ & R vs IF* $^{*}$ \\
\hline Basal ACTH $(\mathrm{pg} / \mathrm{ml})$ & $10 \pm 7$ & $24 \pm 21$ & $45 \pm 26$ & 0.1 & 0.003 \\
Peak ACTH $(\mathrm{pg} / \mathrm{ml})$ & $11 \pm 8$ & $43 \pm 25$ & $139 \pm 97$ & 0.003 & 0.002 \\
Basal cortisol (nmol/l) & $111 \pm 132$ & $249 \pm 134$ & $536 \pm 121$ & 0.058 & 0.002 \\
Peak cortisol $(\mathrm{nmol} / \mathrm{l})$ & $147 \pm 166$ & $478 \pm 231$ & $822 \pm 390$ & 0.013 & 0.003 \\
\% ACTH increment & $26 \pm 64$ & $129 \pm 137$ & $205 \pm 129$ & 0.035 & 0.008 \\
\% Cortisol increment & $64 \pm 115$ & $99 \pm 42$ & $47 \pm 39$ & 0.139 & 0.205 \\
\hline
\end{tabular}

* Mann-Whitney U test. 

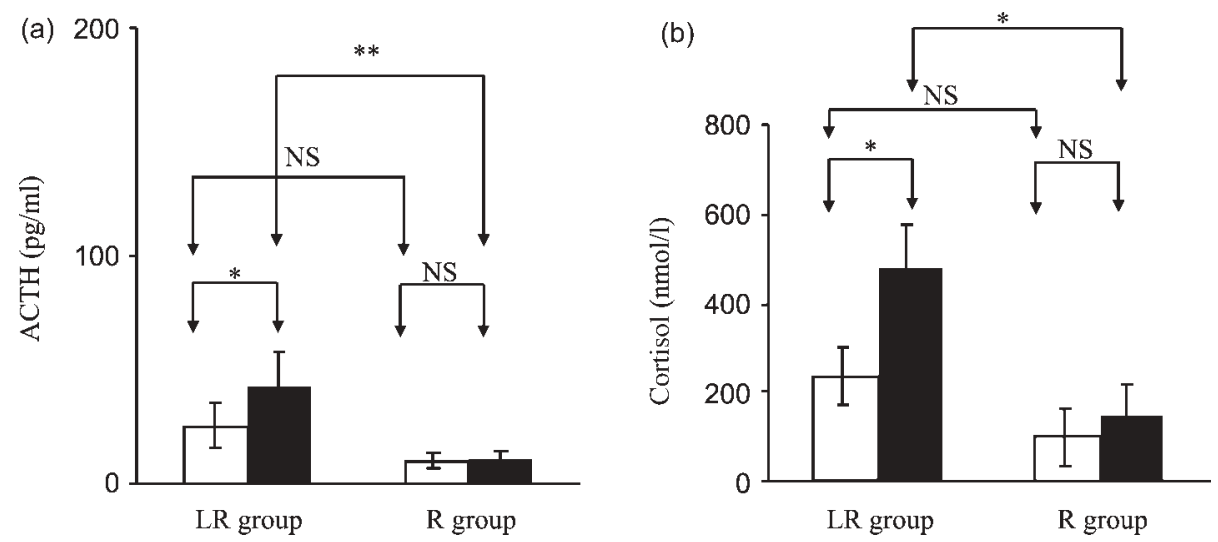

Figure 2 Mean \pm S.D. basal (open bars) and peak (solid bars) plasma (a) ACTH (pg/ml) and (b) cortisol (nmol/l) during the desmopressin test in twelve patients in the R group and in the five patients in the LR group. Statistical analysis was performed by Mann-Whitney's $U$ test except for the differences between basal plasma ACTH and cortisol values and their secretion peaks which was performed using the Wilcoxon test. ${ }^{*} P<0.05,{ }^{\star \star} P<0.01$, NS, not significant.

Table 3 Performance characteristics of the desmopressin test as determined by ROC analysis in twelve patients in the R group and five patients in the LR group.

\begin{tabular}{lcccr}
\hline R vs LR & Sensitivity (\%) & Specificity (\%) & Positive PV (\%) & Negative PV (\%) \\
\hline Peak ACTH $\geq 22 \mathrm{pg} / \mathrm{ml}$ & 80 & 100 & 100 & 92 \\
ACTH rise $\geq 35 \%$ & 80 & 75 & 57 & 90 \\
Peak cortisol $\geq 350 \mathrm{nmol} / \mathrm{l}$ & 80 & 92 & 80 & 92 \\
Cortisol rise $\geq 14 \%$ & 100 & 67 & 56 & 100 \\
\hline
\end{tabular}

$\mathrm{PV}$, predictive value.

long-term remission (61 months) had a mean cortisol 7 days after surgery above $100 \mathrm{nmol} / \mathrm{l}(107 \mathrm{nmol} / \mathrm{l})$, and in the five patients who had a later recurrence, early postoperative cortisol was undetectable in two and between 28 and $99 \mathrm{nmol} / \mathrm{l}$ in the other three. Therefore, early postoperative cortisol did not allow an adequate prediction of the long-term outcome of surgery in our patients. In the present study, we have thus shown the potential usefulness of a desmopressin test in the postoperative follow-up of patients with Cushing's disease.

Previous studies have shown the potential interest of the vasopressin (AVP) analog desmopressin in the diagnosis of Cushing's disease due to an overexpression of the V1b/V3 subtype of the arginine vasopressin receptor in adenomatous vs normal corticotroph cells $(24$, 33). Indeed, taking together the results from several studies in a total of 192 subjects with Cushing's disease, a positive cortisol response to desmopressin was reported on average in $92 \%$ of patients, and an ACTH response in $85 \%(17,25,26,30,31,34)$. Definitions for positive response may, however, differ slightly between authors who also used different assays with distinct characteristics. In the largest short-term published series an ACTH increase of 30\% and a cortisol increase of $20 \%$ were considered as positive responses (17). In the latter series, 50 of 87 patients tested preand postoperatively showed disappearance of a positive ACTH response to desmopressin after surgery, of whom four were surgical failures, with a mean follow-up of 17 months (range, 2-54 months).

With a median follow-up of 4 years (minimum, 2years; range, 24-141 months), we analyzed the endocrine outcome of 22 operated patients, five of whom could be classified into the IF group because of a lack of biochemical cure: all of them indeed had elevated 24-h plasma cortisol and UFC values at the first postoperative evaluation. Among the 17 remaining

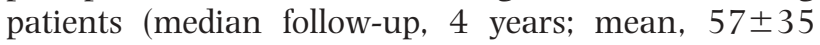
months), based on peak ACTH values, the postoperative desmopressin test was predictive of a later recurrence with a positive predictive value of $100 \%$ and a negative predictive value of $92 \%$. Indeed ACTH or cortisol peak responses yielded the best predictive values when expressed in absolute values.

A potential limitation of the use of this test is represented by the existence of false negative responses in patients with Cushing's disease; these were found in $10-20 \%$ of patients $(27,28,30)$. Furthermore, we obviously cannot rule out that some of the patients currently classified as in remission will experience a later recurrence, resulting in an underestimation of the positive predictive value of the test and overestimation of its negative predictive value. This is made still more likely by the fact that the mean duration of follow-up was significantly longer in the LR group than in the $\mathrm{R}$ group. However, when all of our patients were categorized into each outcome group at 2 years of follow-up to control 
for a possible follow-up bias, only one patient who had been classified into the LR group because of a recurrence occurring 3 years after surgery fell into the $R$ group: using the above-mentioned thresholds in absolute values, the sensitivity and specificity of the test as a predictive factor of recurrence would remain acceptable (75\% and $92 \%$ respectively for ACTH and $75 \%$ and $85 \%$ respectively for cortisol).

In the present study reporting the long-term followup of patients after surgery for Cushing's disease, desmopressin testing appeared as a potentially valuable tool to determine the likelihood of late recurrence of hypercortisolism. This test cannot, however, be recommended as a parameter of biological follow-up in patients who may have a false negative response to desmopressin preoperatively. In addition to previously validated parameters, mainly early postoperative cortisol levels, this test might help to define a subset of patients at higher risk of recurrence. The prognostic value of this test needs to be further validated by prospective studies.

\section{Acknowledgements}

The authors wish to thank Chantal Bertorello for help in statistical analyses.

\section{References}

1 Bochicchio D, Losa M \& Buchfelder M. Factors influencing the immediate and late outcome of Cushing's disease treated by transsphenoidal surgery: a retrospective study by the European Cushing's disease survey group. Journal of Clinical Endocrinology and Metabolism $1995 \mathbf{8 0} 3114-3120$.

2 Boggan J, Tyrell B \& Wilson C. Transsphenoidal microsurgical management of Cushing's disease. Journal of Neurosurgery 1983 59 195-200.

3 Tyrell B, Brooks R, Fitzgerald P, Cofoid P, Forsham P \& Wilson C. Selective trans-sphenoidal resection of pituitary microadenomas. New England Journal of Medicine 1978298 753-758.

4 Bakiri F, Tatai S, Aouali R, Semrouni M, Derome P, Chitour F \& Benmiloud M. Treatment of Cushing's disease by transsphenoidal, pituitary microsurgery: prognosis factors and long-term follow-up. Journal of Endocrinological Investigation $1996 \quad 19$ 572-580.

5 Barrou Z, Abecassis JP, Guilhaume B, Thomopoulos P, Bertagna $\mathrm{X}$, Derome P, Bonnin A \& Luton JP. Imagerie par résonance magnétique dans la maladie de Cushing. Presse Medicale 199726 $7-11$.

6 Guilhaume B, Bertagna X, Thomsen M, Bricaire C, Vila-Porcile E, Olivier L, Racadot J, Derome P, Laudat M, Girard F, Bricaire H \& Luton JP. Transsphenoidal pituitary surgery for the treatment of Cushing's disease: results in 64 patients and long term followup studies. Journal of Clinical Endocrinology and Metabolism 1988 66 1056-1064.

7 Invitti C, Pecori Giraldi F, De Martin M \& Cavagnini F. Diagnosis and management of Cushing's syndrome: results of an Italian multicenter study. Journal of Clinical Endocrinology and Metabolism $199984440-448$.

8 Orth D. Medical progress: Cushing's syndrome. New England Journal of Medicine $1995332791-803$.
9 Robert F \& Hardy J. Cushing's disease: a correlation of radiological, surgical and pathological findings with therapeutic results. Pathology Research and Practice 1991187 617-621.

10 Tagliaferri M, Berselli M \& Loli P. Transsphenoidal microsurgery for Cushing's disease. Acta Endocrinologica 1986113 5-11.

11 Burke C, Adams C, Esiri M, Morris C \& Bevan J. Transsphenoidal surgery for Cushing's disease: does what is removed determine the endocrine outcome? Clinical Endocrinology 199033 525-537.

12 Newell-Price J. Transsphenoidal surgery for Cushing's disease: defining cure and following outcome. Clinical Endocrinology $20025619-21$.

13 Devoe D, Miller W, Conte F, Kaplan S, Grumbach M, Rosenthal S, Wilson C \& Gitelman S. Long-term outcome in children and adolescents after transsphenoidal surgery for Cushing's disease. Journal of Clinical Endocrinology and Metabolism $1997823196-3202$.

14 Leinung M, Kane L, Scheithauer B, Carpenter P, Laws E \& Zimmerman D. Long term follow-up of transsphenoidal surgery for the treatment of Cushing's disease in childhood. Journal of Clinical Endocrinology and Metabolism 199580 2475-2479.

15 Mampalam T, Tyrell B \& Wilson C. Transsphenoidal microsurgery for Cushing's disease. Annals of Internal Medicine 1988109 487-493.

16 Pieters G, Hermus A, Meijer E, Smals A \& Kloppenborg P. Predictive factors for initial cure and relapse rate after pituitary surgery for Cushing's disease. Journal of Clinical Endocrinology and Metabolism $1989691122-1126$.

17 Losa M, Mortini P, Dylgjeri S, Barzaghi R, Franzin A, Mandelli C \& Giovanelli M. Desmopressin stimulation test before and after pituitary surgery in patients with Cushing's disease. Clinical Endocrinology $20015561-68$.

18 Vallette-Kasic S, Dufour H, Mugnier M, Trouillas J, Valdes-Socin H, Caron P, Morange S, Girard N, Grisoli F, Jaquet P \& Brue T. Markers of tumor invasion are major predictive factors for the long-term outcome of corticotroph micradenomas treated by transsphenoidal adenomectomy. European Journal of Endocrinology $2000143761-768$.

19 Nishizawa S, Oki Y, Ohta S, Yokota N, Yokoyama T \& Uemura K. What can predict postoperative 'endocrinological cure' in Cushing's disease? Neurosurgery $1999 \mathbf{4 5}$ 239-244.

20 Sonino N, Zielezny M, Fava G, Fallo F \& Boscaro M. Risk factors and long-term outcome in pituitary-dependent Cushing's disease. Journal of Clinical Endocrinology and Metabolism $1996 \mathbf{8 1}$ 2647-2652.

21 Toms G, McCarthy M, Niven M, Orteu C, King T \& Monson J. Predicting relapse after transsphenoidal surgery for Cushing's disease. Journal of Clinical Endocrinology and Metabolism $1993 \mathbf{7 6}$ 291-294.

22 Antoni F. Novel ligand specificity of pituitary vasopressin receptors in the rat. Neuroendocrinology $198439186-188$.

23 Sugimoto T, Saito M, Mochizuki S, Watanebe Y, Hashimoto S \& Kawashima H. Molecular cloning and functional expression of a cDNA encoding the human V1b vasopressin receptor. Journal of Biological Chemistry $199426927088-27092$.

24 de Keyzer Y, Rene P, Beldjord C, Lenne F \& Bertagna X. Overexpression of vasopressin (V3) and corticotrophin-releasing hormone receptor genes in corticotroph tumours. Clinical Endocrinology $1998 \mathbf{4 9} 475-482$.

25 Newell-Price J, Perry L, Medbak S, Monson J, Savage M, Besser M \& Grossman A. A combined test using desmopressin and corticotropin releasing hormone in the differential diagnosis of Cushing's syndrome. Journal of Clinical Endocrinology and Metabolism 1997 82 176-181.

26 Malerbi D, Mendonça B, Liberman B, Toledo S, Corradini M, Cunha-Neto M, Fragoso M \& Wajchenberg B. The desmopressin stimulation test in the differential diagnosis of Cushing's syndrome. Clinical Endocrinology 199338 463-472.

27 Moro M, Putignano P, Losa M, Invitti C, Maraschini C \& Cavagnini F. The desmopressin test in the differential diagnosis between Cushing's disease and pseudo-Cushing states. Journal of Clinical Endocrinology and Metabolism 2000 85 3569-3574. 
28 Terzolo M, Reimondo G, Ali A, Borretta G, Cesario F, Pia A, Paccotti P \& Angeli A. The limited value of the desmopressin test in the diagnostic approach to Cushing's syndrome. Clinical Endocrinology 200154 609-616.

29 Dickstein G, DeBold C, Gaitan D, Decherney G, Jackson R, Sheldon W, Nicholson W \& Orth D. Plasma corticotropin and cortisol responses to ovine corticotropin-releasing hormone (CRH), arginine vasopressin (AVP), CRH plus AVP, and CRH plus metyrapone in patients with Cushing's disease. Journal of Clinical Endocrinology and Metabolism 199681 2934-2941.

30 Colombo P, Passini E, Re T, Faglia G \& Ambrosi B. Effect of desmopressin on ACTH and cortisol secretion in states of ACTH excess. Clinical Endocrinology 199746 661-668.

31 Tsagarakis S, Kaskarelis I, Kokkoris P, Malagari C \& Thalassinos N. The application of a combined stimulation with $\mathrm{CRH}$ and desmopressin during bilateral inferior petrosal sinus sampling in patients with Cushing's syndrome. Clinical Endocrinology 2000 $52355-361$
32 Colombo P, Dell'Asta C, Barbetta L, Re T, Passini E, Faglia G \& Ambrosi B. Usefulness of the desmopressin test in the postoperative evaluation of patients with Cushing's disease. European Journal of Endocrinology $2000143227-234$

33 Dahia P, Ahmed-Shuaib A, Jacobs R, Chew S, Honegger J, Fahlbusch R, Besser G \& Grossman A. Vasopressin receptor expression and mutation analysis in corticotropin-secreting tumors. Journal of Clinical Endocrinology and Metabolism 1996 81 1768-1771.

34 Sakai Y, Horiba N, Tozawa F, Sakai K, Kuwayama A, Demura H \& Suda T. Desmopressin stimulation test for diagnosis of ACTHdependant Cushing's syndrome. Endocrinology Journal 199744 687-695.

Received 16 June 2004

Accepted 13 September 2004 